\title{
An Interview with Boris Hasselblatt
}

\section{Rachel Crowell}

This is an edited version of an interview with Boris Hasselblatt, whose initial two-year term as AMS Secretary began on February 1, 2021. Hasselblatt is a professor at Tufts University. The interview was conducted in fall 2020 by freelance writer Rachel Crowell.

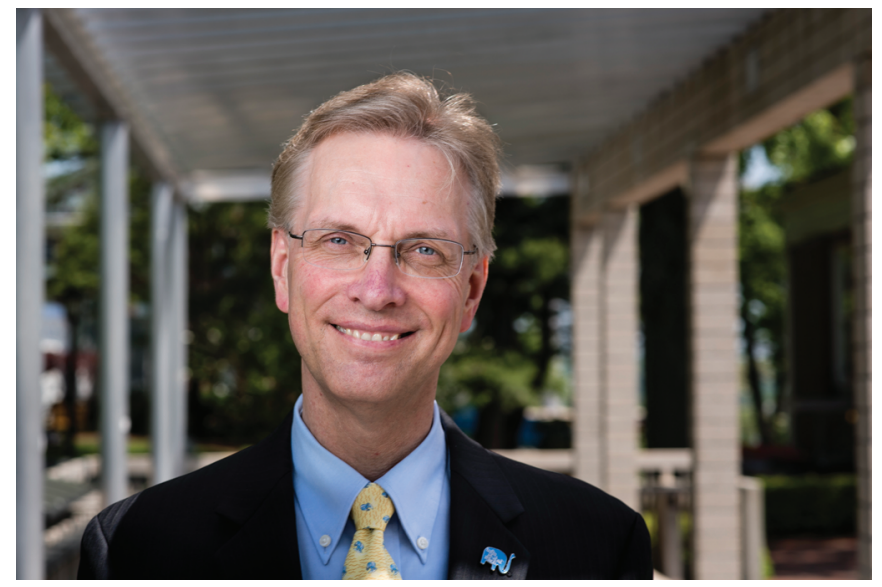

Figure 1. AMS Secretary Boris Hasselblatt.

Notices: When and how did you first discover your passion for mathematics and its community?

Hasselblatt: It was actually a little bit late, because I started out as a physics student. Gradually, over time, I realized that mathematics was what I loved about being a physicist. So I didn't make a change to being a mathematician until sometime in graduate school after I came to the US. But the fun started well before then. I studied in Germany (originally in Berlin), where you matriculate in a department. I was a physics student in a physics department and I was something like a year or two into the overall program and

Rachel Crowell is a freelance math and science writer whose email address is rache1jcrowe11@gmai1. com.

For permission to reprint this article, please contact: reprint-permi ssion aams.org.

DOI: https://dx.doi.org/10.1090/noti2230 taking math classes beyond what was required. I started really having fun taking those, including by working with others. I enjoyed a community of others studying and working on homework together. Mathematics as a community happened in my life even more once I experienced a mathematics graduate program for the first time.

Notices: Your research is "in the modern theory of dynamical systems with an emphasis on hyperbolic phenomena and on geometrically motivated systems." What excites you the most about your research currently?

Hasselblatt: One thing is the collaboration with others. In fact, there was a phase transition in my life, which was that my first papers during and after my doctoral studies were entirely solo papers. I worked on a project together with Amie Wilkinson, who's now at the University of Chicago, and that flipped my mode of operation entirely. I have never, since that moment, done a solo research paper. I have really enjoyed the excitement of working on mathematics together. I like the fun of interacting with another person, but also that the mathematics gets more interesting because ideas come not just from me and out of nowhere, but rather from someone else, from a different perspective, from a different background. Virtually all my papers I've done with others are more interesting than the papers I wrote alone. So that's the excitement. These collaborations are geographically distributed and have involved people with an amazing range of backgrounds. This brought with it a lot more learning than projects done by myself have produced, because I need to absorb these other ideas and 


\section{AMS COMMUNICATION}

insights that my coauthors have in order to make them all part of the joint project.

Notices: What are a few key ideas or questions you have been exploring lately?

Hasselblatt: I'll talk about a project which I've done with my most prolific collaborator: by far, I published the most joint papers altogether with Patrick Foulon. They have covered a few different subjects, but the common theme is contact flows, and we just finished the second paper on the construction of new examples of these. He had thought up a surgery construction, which means cutting something up and sewing it back together, just like what surgery is supposed to be, to produce new examples of flows that I might describe as fake mechanical flows. Technically, these are called contact flows. One starts with free particle motion, which is also called the geodesic flow, and does this cutting and gluing, and the effect is that the resulting flow is definitely no longer of that same mechanical nature, but it retains the contact structure. That was a novelty of our initial paper on the subject. And then already quite some time ago, and in a significant way, we got into studying these a little bit more deeply. We looked into how the resulting flow is more complicated, in the sense of entropy or the typical exponential complexity. And it was interesting in two ways, one of which was that we more deeply understood these, and we are producing interesting new phenomena. And the other thing was that when Patrick Foulon gave a talk about this, Anne Vaugon came on board; she is, as well, a French mathematician. And this completely transformed the project and made it much broader by bringing in an enormous depth of contact topology, which was a subject about which I previously heard, but which I never really understood. And this produced something much more interesting and much broader. So the underlying ideas are that of producing new dynamical systems from old ones through surgery, and in this case, the novelty specifically that they retain this contact structure, which was new, and that that now turns out to, surprisingly, connect to contact topology, whose origins overlap with those of dynamical systems. We may have contributed to creating a substantial overlap between these two fields by this piece of work.

Notices: Why did you decide to apply for the position as Secretary of the American Mathematical Society?

Hasselblatt: It was several things coming together. One, I have to say, was encouragement by people to apply. Bryna Kra in particular, who has been quite involved with the AMS, encouraged me to apply, because she thought I might actually be good at this job. The more I learn about the job, the more daunting it seems. But the hope is that, in the end, she turns out to have been right.

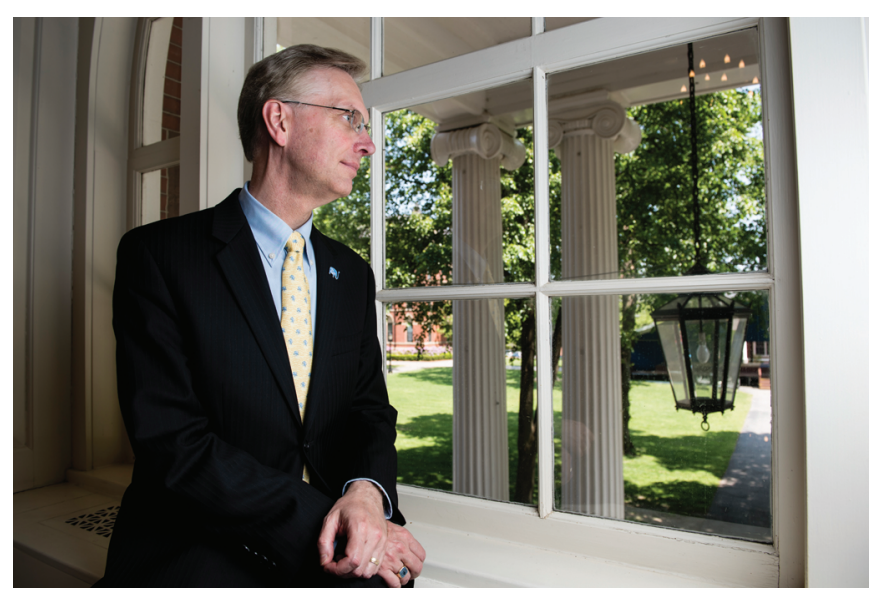

Figure 2. Boris Hasselblatt.

I've been an AMS member for a long time, since my graduate school days and continuously ever since. I've appreciated what the Society does. I have been involved in mathematics in ways that go beyond doing mathematics, like as department chair, organizing conferences, and the like; and in university administration as associate provost for a while. This seemed like an opportunity to bring these skills to bear, but in a new context where I could play a role in leadership or administration in a way that supports something larger than myself, a leading organization that is strong and well run, that is serving the mathematics community.

Another attraction is simply that this is a new challenge. I am learning now, and I will learn even faster once the job really begins. And then hopefully, I will be able to make a contribution to how the AMS can serve the community and science as well.

Notices: What are some of your biggest priorities as the new Secretary?

Hasselblatt: That's a good question. I'll be careful in answering it, because the Secretary, of course, is not meant to be at the forefront of policy or making changes. It is a role that is much more focused on keeping the trains running, having some leadership in the scientific program. It is also not an elected role. So I will try to be careful where I weigh in and how I do. I am not coming in with change priorities, but together with the Executive Director I am hoping to maintain and strengthen the way a lot of the mechanics of the AMS work. I'm really proud of what the AMS and previous Secretaries have done. And one big part of the Secretary's job that may be most suited to thinking about where I see making a difference are the Joint Mathematics Meetings and the sectional meetings. The meetings program of the AMS is important for our community, and it is well supported by the meetings department of the AMS. But it is the Secretariat, which means the Secretary and the 
Associate Secretaries, in crucial ways, that have a lot to do with how these meetings go, both whether a given meeting runs well, but also how the meetings are envisioned. And I aim to make sure that the Joint Mathematics Meetings retain the breadth they had when they were joint with other mathematics societies as co-organizers. The Associate Secretaries and I look forward to supporting broader Joint Mathematics Meetings and sectional meetings. This includes diversity in every dimension and is part of increasing the diversity and inclusivity of these meetings, of the American Mathematical Society, of the profession, and of mathematics. And this is already an urgent priority for the AMS. The Joint Mathematics Meetings will be run by the American Mathematical Society alone. I am glad that we already have structures in place to host broader meetings with inspired programming that will make these meetings as successful as they were while they were run jointly with the MAA and have the same breadth. In fact, more breadth, offerings of broader interest, and a lot of vibrancy are coming in the future.

Notices: What are you most looking forward to about this position?

Hasselblatt: Initially, some of the learning because there's still a lot of the detail that I will be learning. But fundamentally, what makes this job interesting is that the American Mathematical Society is an organization that's well run in the sense of being really rich in highly competent and engaged volunteers, and that the operation in Providence is really solid and has a lot of talent. When working with the committees of volunteers, as well, I have these two sets of people, staff and volunteers, that form the operation of the AMS. I am grateful to be working with smart people, committed to a common cause, pulling in the same direction. Supporting the development of ideas, contributing maybe in a small way, and helping the whole enterprise succeed. The Secretary's role to a great extent as well is to prepare business meetings and support the communication between the various committees and the Council or Board of Trustees to whom they report. So facilitating these interactions between entities as well as among individuals, on committees and across committees, to let us all lead the AMS into the future. This combination of creativity working together in a well-run organization is going to be rewarding.

Notices: What does acceptance of this position mean to you?

Hasselblatt: It's a life-changing challenge and a chance to contribute. It may have helped when I applied for the job that I didn't fully understand the challenges or how big the job is. But now that I'm learning, I am looking forward to the opportunities these challenges bring: to learn, grow, and build while working in a community and a team of excellent staff. It is huge that I am being so well mentored and supported by Carla Savage, the current Secretary, who will stay onboard to hold my hand for about half a year after I take on this challenge. The inspiring leadership of Catherine Roberts and the brilliance of Steven Ferrucci and Laura Byrum put me in a position to succeed. Together with strong staff and Associate Secretaries who so generously volunteer their time, I look forward to enjoying every year and hope that things will run even better and grow more exciting every year, in terms of what the AMS does, how effective the AMS is, how interesting the offerings are that the AMS has for the mathematical community, and how much difference we make altogether.

Notices: Is there anything that you would like to say about the significance of your predecessor's contributions as Secretary?

Hasselblatt: They are pervasive and run deep, and I will be in a much better position to say that some time into my job because I will only fully appreciate just how much Carla Savage has done when I have to do it myself. I already appreciate the extent to which she understands, supports, and advances the AMS in a myriad of small details, in the big picture, and in her incredible wisdom, which shows in the way she interacts with people and the various parts of the institution, as well as in the gentle ways in which guidance is provided when needed. She supports the AMS committees, the Council, the Board of Trustees, and the President. She keeps in mind how the whole organism works to make sure that all parts of it are as efficient and as effective as possible by being connected to each other and advancing their goals in concert with the overall priorities of the Society. I think this is just a really small way in which one can describe what Carla has done. A better appraisal will come from those who have worked closely with her for a longer time than I have. And from me once I can more fully appreciate what the job is and how well she's done it as I try to keep up with the example that she has been setting.

Notices: What are a few things you enjoy when you're not doing math?

Hasselblatt: One of them is music. I have been singing since my high school days. And in the last two decades, I've done it at Trinity Church in Boston, where there is a choir that is better run than any one I ever joined before. It's music done with a purpose, both at high quality and with an important service to community in ministry.

Some aspects of travel are fun. This has involved sabbaticals and travels I have undertaken just with my wife. Some trips were to exotic locales, others local, such as fall foliage trips in New England. 


\section{AMS COMMUNICATION}

Music is something that I find resonates; maybe you think of the trope that mathematics and music go together. But the deeper thing is that music, like mathematics, involves creativity but within a set of rules-although maybe that most importantly applies to composers or solo performers. For me, it has provided a community in which the pursuit of excellence and purpose is exercised together with others. In a good choir, every one member takes responsibility for the whole group and yet can also feel secure in being supported by the group as music is happening. That reflects many ways in which I had previously been enjoying my engagement with my university and working and living in my department. There is a collegial environment in which people pull their weight but can also trust others to do so. And that is the kind of life I look forward to in my engagement with the AMS as Secretary: there are going to be smart people who are very engaged, and you are pulling in the same direction taking responsibility, but you can likewise count on others to share that responsibility. That explains to some extent things that resonate with the way I look forward to embracing this new assignment.

\section{Credits}

Figures are courtesy of the Trustees of Tufts College and Momo Shinzawa.
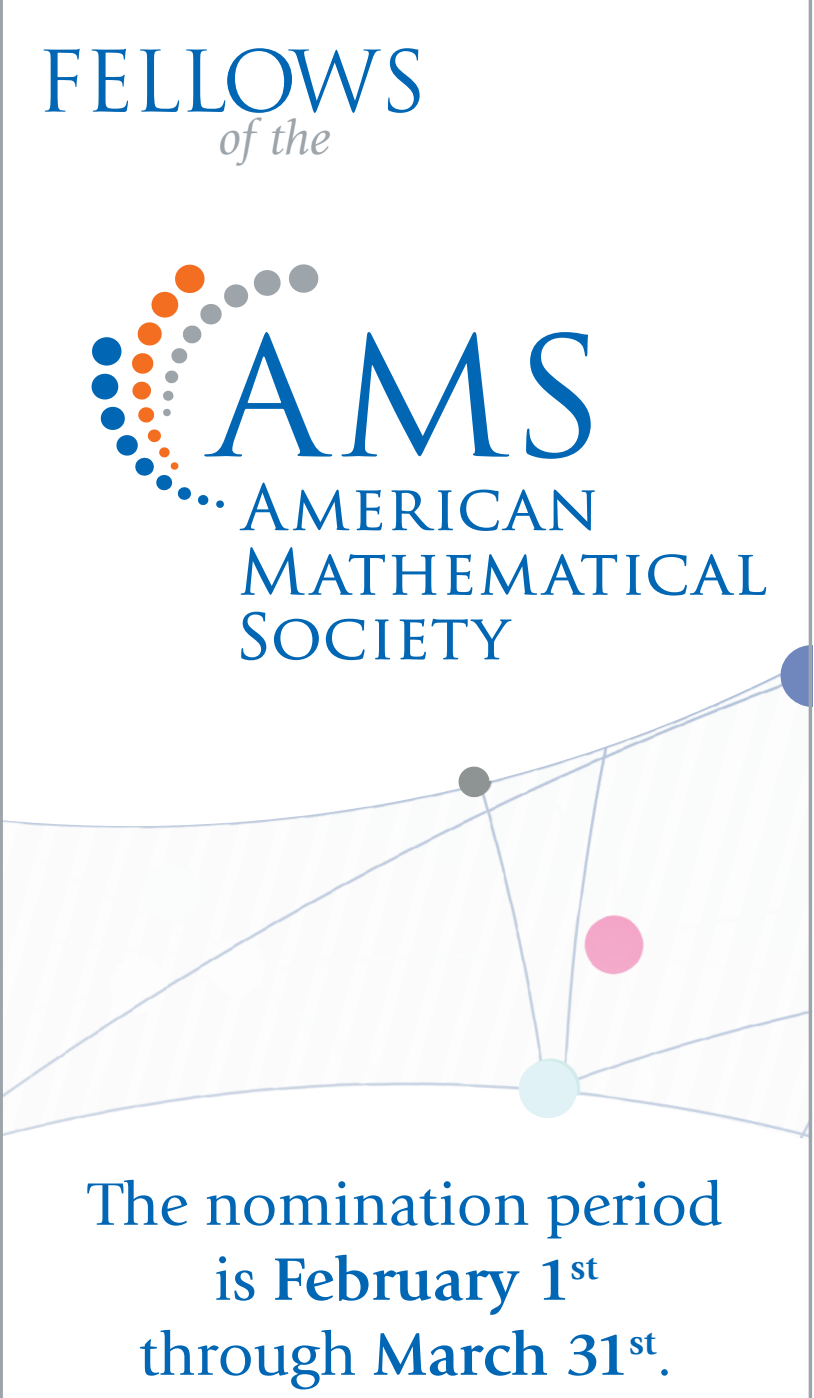

Learn how to make or support a nomination in the Requirements and Nominations Guide at: www.ams.org/ams-fellows

Questions:

Contact AMS staff at

800.321.4267, ext. 4096

or by email at

amsfellows@ams.org 